http://jmscr.igmpublication.org/home/

ISSN (e)-2347-176x ISSN (p) 2455-0450

crossref DOI: https://dx.doi.org/10.18535/jmscr/v10i1.28

\title{
Important Predictors of Low Birth Weight in Prenatal Care of Mothers
}

\author{
Authors \\ Dr Smiti Narain*, Dr Hari Shanker Joshi, Dr Tanmay Prasad \\ Department of Community Medicine, Rohilkhand Medical College and Hospital, Bareilly \\ *Corresponding Author \\ Dr Smiti Narain
}

\begin{abstract}
Low birth weight (LBW) has been defined by the World Health Organization as weight at birth of less than 2,500 grams. LBW is a prospective marker of future growth and development and a retrospective marker of mothers' nutritional and health status and as sensitive index of nation's health and development.

Objectives: The purpose of the study was to regroup the different risk factors in the LBW and arrange them for a better clinical utility tool.

Materials and Methods: Present study was a cross sectional type interviewing all mothers delivering live born singleton neonate in study place with pretested predesigned schedule. Statistical analysis was done using SPSS software and chi square test.

Results: $L B W$ was found to be more common in extremes of maternal age, mothers living in rural areas, mothers who were illiterate and belonged to lower socioeconomic class. LBW was more profound in primi para, mothers with inadequate antenatal visits, and mothers with past history of abortions, pre term babies and small for gestational age babies. $L B W$ was more common in pregnant mothers taking less than 3 meals per day, not taking fruits, jaggery or Iron Folic acid. LBW was found to be more in mothers taking alcohol, smoking and doing heavy physical work during pregnancy.

Conclusion: The present study compiled the significant factors relating to LBW babies and tabulated them for better referential purposes and use it as a useful clinical tool.

Keywords: Low birth weight, predictors, antenatal.
\end{abstract}

\section{Introduction}

"Today's children are tomorrow's citizens of a country."Thus the normal health and growth of children plays an important role in the prosperity of a country. Number of factors like maternal, socioenvironmental and genetic are responsible for the normal health, development and survival of children $^{1}$. To achieve this proper care is to be given even before a woman conceives, during pregnancy, delivery and after the birth.
The children are at an increased risk of mortality and morbidity than the general population. This is more so in the first year of life. More than half the infant deaths occur in the first 28 days of life. Most of these take place in the first week of life. The major causes of these deaths are due to birth asphyxia, hypothermia, infections and home delivery under supervision of untrained dais. Babies born with a low birth weight are at higher risk of dying. In the developing countries Infant mortality rate is very high compared to developed 
countries. Of the various causes of Infant mortality, either in developing or developed countries, birth weight is one of the important factors for the survival, normal growth and development of a child ${ }^{2}$.

Low birth weight has been defined by the World Health Organization (WHO) as weight at birth of less than 2,500 grams ${ }^{3}$.

Low birth weight is a prospective marker of future growth and development and a retrospective marker of mothers' nutritional and health status ${ }^{1}$. The low birth weight is considered as sensitive index of nation's health and development ${ }^{4}$.

In India, the prevalence of LBW has significantly declined from $20.4 \%$ (95\%CI 19.4-21.4) to $16.4 \%$ (95\% CI 16.1-16.8) in the last decade. Though the fall in prevalence is sluggish over a decade but it may be admired as a decreasing trend, despite the magnitude of maternal and child health programs implemented during the same period ${ }^{5}$.

Preterm birth and intra uterine growth restriction are considered as amongst the strongest factors associated with low birth weight and consequent peri natal and neonatal mortality. These have also been linked to later adulthood morbidities such as heart disease, stroke, hypertension, diabetes etc ${ }^{6}$. Many determinants associated with LBW and their association with IUGR have been discussed such as maternal smoking, alcohol intake, poor diet, mother's weight, demographics, obstetric history and other values ${ }^{7,8}$.

The purpose of the study was to regroup the different aspects in the LBW and arrange them for a better clinical utility tool while assessing the mother during the antenatal phase. maternal history.

\section{Material and Method}

Study Area: Study was carried out in postnatal ward of a hospital associated to a medical college. Study period: January 2014 to December 2015.

\section{Study Population}

Inclusion Criteria: All mothers delivering live born neonate in study place.

\section{Exclusion Criteria}

1) Mothers with multiple pregnancies.

2) Neonates with congenital malformations, chromosomal anomalies and hemolytic disease of the newborn.

Nature of Study: Cross sectional study.

Sample Size: 600 (taken by consecutive sampling technique.)

Study Tool: Pretested, predesigned schedule.

Data Collection: Schedule was prepared and pretested by carrying out pilot study with a sample of 40 subjects after taking clearance from the ethical committee. Interviews with the mother were conducted after explaining the purpose, benefits, risks and confidentiality of the study. Schedule contained pertinent questions regarding residence, socioeconomic and education status, diet history, intake of iron folic acid and maternal haemoglobin.

Data Analysis: By SPSS version 21 program in the computer and appropriate statistical tests.

\section{Results}

The present study conducted with the objectives to determine proportion of LBW and their associated determinants and to finally group them as a useful clinical assessment tool.

I) Patient particulars that were assessed and their association with LBW found to be statistically significant $(\mathrm{p}<0.05)$ are as follows:

Age of Mother: Proportion of LBW was highest in extremes of maternal age. In more than 30 years and less than 18 years age group, LBW proportion was as high as $50 \%$ and $40 \%$ respectively as compared to $13.1 \%$ and $18.8 \%$ in $18-24$ and $25-30$ years age group respectively.

Demographic Region: In the present study, maximum number of mothers 357(59.5\%) were from urban area. The percentage of LBW was found to be more in babies of mother belonging to rural area $(23.9 \%)$ as compared urban area (13.4\%).

Educational Status: The percentage of low birth weight babies was found to be higher in illiterate women $(59.7 \%)$. The low birth weight percentage 
decreased with increase in educational status. The percentage of low birth weight was inversely proportional to educational standards.

Socioeconomic Status: The proportion of LBW babies increased as socioeconomic status decreased i.e higher the socioeconomic status lower is the proportion of LBW. The percentage of low birth weight babies was low (6.3\%) in upper class. It increased with decrease in socio economic status and was highest (66.7\%) in lower class.

\section{II) Among the Obstetric and Gynecological factors that were assessed}

Parity: The percentage of low birthweight babies was $16.4 \%$ in para 1 mothers. It decreased in parity $2(9.2 \%)$. After para 2 nd an increasing trend of LBW was seen $(14.5 \%, 31.4 \%, 55 \%$ in para $3 \mathrm{rd}, 4$ th and 5th respectively).

Past history of abortions: In 64 mothers with past history of abortion, $37.5 \%$ had LBW while LBW percentage was only $15.3 \%$ in mothers with no such history. The association was found to be statistically significant.

Past history of preterm and SFG: The proportion of LBW babies was found to be high among mothers with past history of preterm/small for gestational age or LBW (59.8\%) as compared to $7.1 \%$ in mothers with no such history. The difference was found to be highly significant $(\mathrm{p}<0.000)$.

Past history of ANC: LBW babies were found more $(59.2 \%)$ in mothers with inadequate antenatal visits ( $<4$ visits). Proportion of LBW was very high in mothers who had never taken any antenatal visits (66.7\%) and among those who had taken antenatal visits, LBW percentage was found to be highest in those who initiated antenatal visit in 3rd trimester as compared to those in 1 st and 2nd trimester.

\section{III) Nutritional History}

Number of meals: Proportion of LBW was much higher $(51.8 \%)$ in babies born to mothers taking less than 3 meals per day as compared to those taking 3 meals per day or more (14\% and $4.9 \%$ respectively). Hence a decreasing trend in proportion of LBW with increase in number of meals taken per day during pregnancy.

Fruits and Jaggery intake: Proportion of LBW was much higher (48\%) in babies born to mothers not taking fruits as compared to those taking fruits 1-3 times per week (13\%) and more than 3 times per week $(1.5 \%)$. Hence a decreasing trend in proportion of LBW with increase in fruits intake during pregnancy.

Percentage of LBW was higher (20.2\%) in babies of mother who did not take jaggery during their pregnancy as compared to those who take jaggery $(9.3 \%)$.

IFA (Iron and folic acid)/Folic acid: The proportion of LBW was low among those mothers who were taking iron folic acid during pregnancy. In mothers who took adequate iron folic acid tablets (100 or more) during pregnancy, the percentage of LBW born was only $3.4 \%$ as compared to $31.6 \%$ in those who took less than 100 tablets.

\section{IV) Personal Habits}

Smoking and alcoholism: Percentage of LBW was found to be higher $(65.4 \%)$ in mothers with history of smoking during pregnancy as compared to those who do not smoke (15.5\%). This association was highly significant $(\mathrm{p}<0.000)$. Percentage of LBW was found to be higher $(64.3 \%)$ in mothers with history of alcohol intake during pregnancy as compared to those who do not take alcohol (16.6\%). This association was highly significant $(\mathrm{p}<0.000)$.

Physical work: LBW was found to be higher (54.7\%) among mothers who did heavy physical work during pregnancy as compared to mothers with moderate $(15.2 \%)$ and sedentary physical activity during pregnancy. A significant association was found between physical activity level of mother during pregnancy and birth weight of baby $(\mathrm{p}<0.05)$. 
Table 1: Predictors of Low birth weight as key factors and their elements:

\begin{tabular}{|l|c|c|c|c|}
\hline Factors & Patient particulars & $\begin{array}{c}\text { Obstetric and } \\
\text { gynecologic history }\end{array}$ & Nutritional history & Personal habits \\
\hline \multirow{3}{*}{ Key elements } & Age of mother & Parity & Number of meals & Smoking \\
\cline { 2 - 5 } & Geographic area & History of abortion & Iron and folic acid & Alcoholism \\
\cline { 2 - 5 } & Literary status & History of preterm, SFG & Fruits intake & Physical work \\
\cline { 2 - 5 } & Socioeconomic status & Inadequate ANC & Jaggery intake & \\
\hline
\end{tabular}

\section{Discussion}

Deshpande et al found similar findings as our study and had tabulated the results. Age of the mother during delivery, rural background, literacy status of mothers, low socio economic status, parity, past history of abortion, past history of small for gestational age, inadequate ANC care, poor diet, improper intake of iron and folic acid, history of smoking and alcoholism and heavy physical work were all found to be significant factors relating to Low birth weight ${ }^{8}$.

Roy et al reported similar results and also referenced statistical data from NFHS, corroborating their findings ${ }^{5}$.

Khan et al, Roudbari et al and Rizvi et al found similar findings that mothers not taking iron and folic acid had a higher incidence of LBW babies, a similar observation as this study ${ }^{9,10,11}$.

\section{Conclusion}

The present study aims at compiling all the significant factors relating to the low birth weight babies and tabulating them for better referential purposes and use it as a useful clinical adjunctive tool.

These factors (Key patient particulars, Obstetric history, important nutritional history and personal habits) being significantly important are the areas of importance to look for, evaluate and if possible improve to reduce the low birth weight incidences.

\section{References}

1. UNICEF (US). Malnutrition in South Asia: A regional profile. New Delhi: Rosa publications, 1997. P. 23-50.

2. Park K. Park's Text book of preventive and social medicine. $22^{\text {nd }}$ Edition., Jabalpur: M/s Banarsidas Bhanot, 2013; 495-496
3. UNICEF/WHO Low Birth weight, Country, Regional and Global Estimates, 2006, ISBN : 92-806-3832-7

4. Idris MZ, Gupta A, Mohan U, Srivastava AK, Das V. Maternal Health and low birth weight among institutional deliveries. Indian Journal of community medicine 2000; 25(4) : 156-160.

5. Roy A, Akter MZ, Biswas DC. Trends in prevalence of low-birth-weight babies in India. Int J Contemp Pediatr 2021;8:17259.

6. Nobile CG, Raffaele G, Altomare C, Pavia $M$. Influence of maternal and social factors as predictors of low birth weight in Italy. BMC Public Health. 2007;7:192. Published 2007 Aug 3. doi:10.1186/14712458-7-192

7. Kader M, Perera NK. Socio-economic and nutritional determinants of low birth weight in India. N Am J Med Sci. 2014 Jul;6(7):302-8. doi: 10.4103/19472714.136902. PMID: 25077077; PMCID: PMC4114006.

8. D, Deshpande \& Phalke, Deepak \& Peeyuusha, D \& Sushen, Bhatt. (2011). Maternal risk factors for low birth weight neonates: A hospital based case-control study in rural area of Western Maharashtra, India. Natl J Community Med. 2

9. Khan MMA, Mustagir MG, Islam MR, et al. Exploring the association between adverse maternal circumstances and low birth weight in neonates: a nationwide population-based study in Bangladesh. BMJ Open 2020;10:e036162. doi:10.1136/bmjopen-2019-036162 
10. Roudbari M, Yaghmaei $M$ and Soheili $M$. Prevalence and risk factors of low birth weight infants in Zahedan, Islamic Republic of Iran. Eastern Mediterranean Health Journal 2007;13(4):838 845.

11. Rizvi SA, Hathcher J, Jehan I and Qureshi R. Maternal risk factors associated with low birth weight in Karanchi: a case control study. Eastern Mediterranean Health Journal 2007;13(6): 1343-1344. 